\title{
REPORT OF THE TREASURER OF THE PSYCHOMETRIC SOCIETY
}

End-Year Report

December 31, 2011

Starting Cash On Hand 01/01/2011

$\$ 428,757.82$

\section{Income}

Administrative

Dues-Members/CD Sales

Investment Income

$\$ 36,540.00$

Journal

Journal Subscriptions

Royalties

Total Income

$\$ 113,822.00$

Total Available Funds

\section{Disbursements}

5

6

7

8

9

10
Administrative

Accounting Expenses

Bank \& Credit Card Fees

Office Travel \& Expenses

Stipend: Secretary

Stipend: Treasurer

Taxes

Total Administrative

Journal

Editor Asst. \& Office Expenses

Stipend: Editor

Stipend: ARCS Editor

Stipend: Publication Editor

Total Journal

UNC-G Office

Fringe

Indirect Cost

Postage

Salaries

Supplies

Current Services

Total UNC-G Office

Annual Meeting IMPS 2010 Meeting Expense IMPS 2011 Meeting Expense IMPS 2012 Meeting Expense

Total Annual Meeting

\section{Total Disbursements}

Ending Cash On Hand 12/31/11
$\$ 579,986.11$

$-\$ 2,105.26$

$-\$ 2,111.96$

$-\$ 1,612.87$

$-\$ 1,875.00$

$-\$ 1,125.00$

$-\$ 1,798.82$

$\mathbf{- \$ 1 0 , 6 2 8 . 9 1}$

$-\$ 131.40$

$-\$ 3,750.00$

$-\$ 2,000.00$

$-\$ 1,500.00$

$-\$ 7,381.40$

$-\$ 16,958.41$

$-\$ 8,328.01$

$-\$ 2,142.29$

$-\$ 62,649.90$

$-\$ 1,221.38$

$-\$ 308.33$

$\mathbf{- \$ 9 1 , 6 0 8 . 3 2}$

$-\$ 1,499.99$

$-\$ 20,191.88$

$-\$ 965.79$

$-\$ 22,657.66$

-\$132,276.29

$\$ 447,709.82$ 